Journal of The Electrochemical Society, 151 (12) G853-G857 (2004)

G853

\title{
Oxide-Thickness-Dependent Suboxide Width and Its Effect
on Inversion Tunneling Current
}

\author{
Yen-Po Lin a and Jenn-Gwo Hwu ${ }^{\mathrm{a}, \mathrm{b}, \mathrm{z}}$
}

${ }^{a}$ Department of Electrical Engineering, Graduate Institute of Electronics Engineering,

National Taiwan University, Taipei, Taiwan

${ }^{b}$ Department of Electronic Engineering, National United University, Miaoli, Taiwan

\begin{abstract}
Suboxide between $\mathrm{SiO}_{2}$ and $\mathrm{Si}$ examined by current-voltage (I-V) measurement was found to exhibit the thickness-dependent inversion current property. In this work, oxides with thickness ranging from 20 to $40 \AA$ were grown on a single wafer. It was found that in gate injection bias, currents decrease with oxide thickness $\left(T_{\mathrm{ox}}\right)$. However, in the substrate injection region, currents saturate and the saturated levels increase with $T_{\mathrm{ox}}$. From the X-ray photoelectron spectroscopy results, suboxide width was observed to increase with $T_{\mathrm{ox}}$. We believe the minority carriers generated from the suboxide region contributes to the additional current source that lead to the polarity-dependent I-V characteristics in MOS diode.

(C) 2004 The Electrochemical Society. [DOI: 10.1149/1.1813653] All rights reserved.
\end{abstract}

Manuscript submitted November 14, 2003; revised manuscript received May 7, 2004. Available electronically October $29,2004$.

For the shrinkage of metal-oxide semiconductor field effect transistors, (MOSFETs), $\mathrm{SiO}_{2}$ thickness scaling is necessary to meet integrated circuit (IC) requirements. However, while oxide thickness $\left(T_{\mathrm{ox}}\right)$ is thinner than $\sim 3 \mathrm{~nm}$, direct tunneling (DT) instead of Fowler-Nordheim (F-N) tunneling dominates the gate leakage mechanism. A reduction of $2 \AA$ in $T_{\text {ox }}$ leads to an order-ofmagnitude increase in gate leakage current, which is a problematic issue to limit $T_{\text {ox }}$ scaling. ${ }^{1}$ At the same time, the interfacial transition region between $\mathrm{Si}$ and its stable $\mathrm{SiO}_{2}$ becomes a larger fraction of the total oxide layer. Defects presented in this thin region become sensitive to the oxide quality. Therefore, a reliable transition region contributes great technological importance to ultrathin gate oxide quality.

Furthermore, despite that significant gate current is a problematic issue, metal-oxide-semiconductor (MOS) tunneling diodes with ultrathin gate oxides have been utilized in many novel applications, such as on-chip temperature sensors, ${ }^{2}$ light-emitting diodes (LEDs), ${ }^{3}$ and photodetectors. ${ }^{4}$ Unlike MOSFET structures, MOS tunneling diodes exhibit different current-voltage (I-V) characteristics under accumulation and inversion biases. In our recent works, we find the inversion current magnitude is strongly dependent on the interface quality and postoxidation treatments, i.e., postoxidation annealing (POA) and postmetallization annealing (PMA). ${ }^{2}$ Because oxide is not entirely homogeneous, different growth conditions lead to the varied interfacial oxide stoichiometry. This interfacial transition region, i.e., suboxide region $\left(\mathrm{SiO}_{x}, x<2\right)$, was comprehensively studied in many works. ${ }^{5-12}$ The suboxide is mainly composed of crystalline $\mathrm{Si}, \mathrm{SiO}_{2}$, and a high ratio of void, which is formed during the competition between $\mathrm{Si}$ monomer creation and $\mathrm{SiO}$ production. ${ }^{5,6}$ In addition, interpretation of the suboxide width is fraught with ambiguity. Grunthaner et al. showed that the existence of the suboxide region was within $30 \AA$ of the $\mathrm{Si}-\mathrm{SiO}_{2}$ interface from the X-ray photoelectron spectroscopy (XPS) measurement. ${ }^{7}$ Horiguchi and Yoshino found that the interfacial suboxide induced barrier height lowering because $T_{\text {ox }}$ was thinner than $31 \AA^{8}{ }^{8}$ In addition, from the comprehensive studies by Himpsel et al., the interface width was reported in the region of 3-10 $\AA .{ }^{9} 95 \%$ suboxide species was found principally at the interface and an improved growth condition could scale the region to under 1.5 monolayers. ${ }^{10}$ The transition region is responsible for the ultrathin oxide quality and the stability of inversion current for the novel applications. Therefore, a comprehensive study of the relation between suboxide and its characteristics is important while only a few monolayers were utilized in such a thin region.

In this work, p-type MOS diodes were analyzed by I-V with

z E-mail: hwu@cc.ee.ntu.edu.tw voltage sweeps both in accumulation and inversion regions. When the gate is biased negatively, electron tunneling from the metal dominates the gate current $\left(J_{\text {accu }}\right)$. On the contrary, while the gate is positively biased, electron tunneling from the conduction band dominates the detected gate current $\left(J_{\text {inv }}\right) .{ }^{13}$ According to the analytical model, ${ }^{14} J_{\text {inv }}$ is comprised of the interface state generation current $\left(J_{\mathrm{s}}\right)$, trap generation-recombination current in the depletion region $\left(J_{\text {rg-d }}\right)$, and diffusion current from back contact $\left(J_{\text {diff }}\right)$. However, our recent works found that apparently $J_{\text {inv }}$ did not increase with the expanding depletion width but with $T_{\mathrm{ox}}$, which is contrary to the observation in accumulation bias. As shown in Fig. 1, conventional rapid thermal oxidation (RTO) grown oxides of 25,27 , and $29 \AA$ exhibit asymmetric I-V curves in accumulation and inversion biases. The saturated inversion tunneling current was observed to increase with $T_{\mathrm{ox}}$. From this observation, we attribute it to the component of generation-recombination effect from the suboxide close to the interface.

\section{Experimental}

Before oxidation, 3 in. p-type silicon substrates were treated with standard RCA cleaning with final HF dip. To eliminate the oxidation-induced variations, e.g., interface trap density $\left(D_{\mathrm{it}}\right)$, substrate doping $\left(N_{\mathrm{A}}\right)$, and growth temperature, thin $\mathrm{SiO}_{2}$ layers (20-40 $\AA$ ) were grown on a single wafer by tilted anodization in deionized (DI) water. ${ }^{15}$ After anodization, postanodization annealing (PAA) at $850^{\circ} \mathrm{C}$ in $\mathrm{N}_{2}$ ambient was utilized to remove the hydrogen from the films. Afterward, standard lithography and etching processes were used to define a MOS structure with $150 \times 150 \mu \mathrm{m}$ aluminum gate electrode. Oxide thickness $\left(T_{\mathrm{ox}}\right)$ is obtained from ellipsometer $(n=1.46)$ and capacitance-voltage $(\mathrm{C}-\mathrm{V})$ measurement while the gate was biased in the strong accumulation region by the following equation

$$
C_{\mathrm{SiO}_{2}}=\frac{\epsilon_{\mathrm{SiO}_{2}} \times A}{T_{\mathrm{SiO}_{2}}}
$$

where $C_{\mathrm{SiO}_{2}}$ is the gate capacitance, $A$ is the gate area, $\epsilon_{\mathrm{SiO}_{2}}$ is the dielectric constant of the $\mathrm{SiO}_{2}$, and $T_{\mathrm{SiO}_{2}}$ is the oxide thickness. In this work, high-frequency $\mathrm{C}-\mathrm{V}$ curves of $100 \mathrm{~K}$ and $1 \mathrm{MHz}$ were measured and corrected to eliminate the series resistance effect. ${ }^{16}$ Afterward, the two-frequency corrected $\mathrm{C}-\mathrm{V}$ curve was taken to fit the quantum mechanical-considered $\mathrm{C}-\mathrm{V}$ curve to obtain $T_{\mathrm{ox}} \cdot{ }^{17} \mathrm{In}$ addition, oxides with thicknesses of 15,25 , and $35 \AA$ were examined by high-resolution XPS to characterize the $\mathrm{Si}-\mathrm{O}$ bonding conditions from the oxide surface to the interface. 


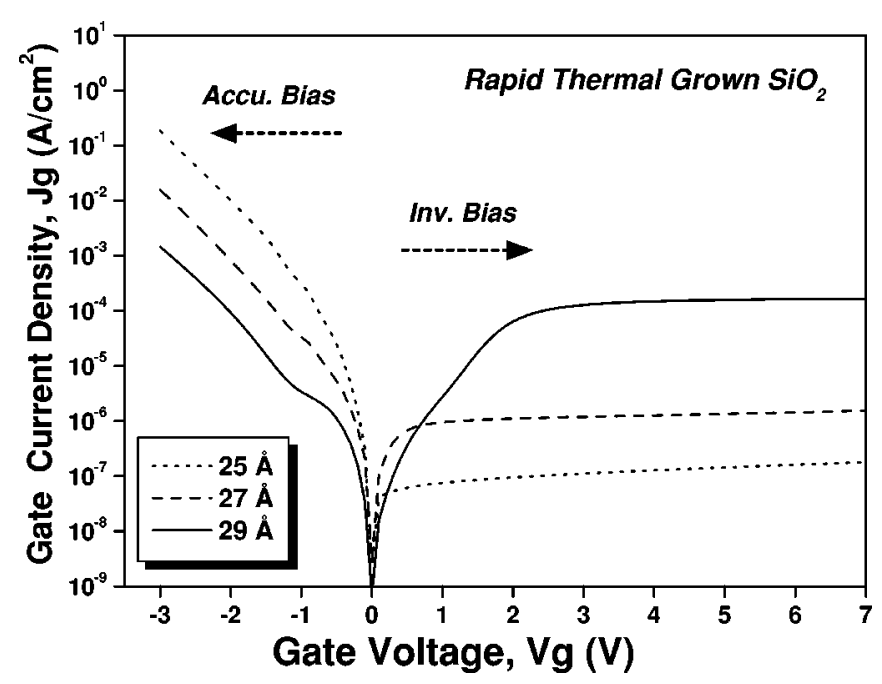

Figure 1. J-V plots of p-type substrate MOS diodes with rapid thermal grown $\mathrm{SiO}_{2}$ of $\mathrm{T}_{\text {ox }}=25,27$, and $29 \AA$. Inversion current $\left(J_{\text {inv }}\right)$ is observed to increase with oxide thickness.

\section{Results and Discussion}

Inversion tunneling current of p-type substrate MOS diodes.After tilted oxidation, oxides with consecutive thicknesses profile

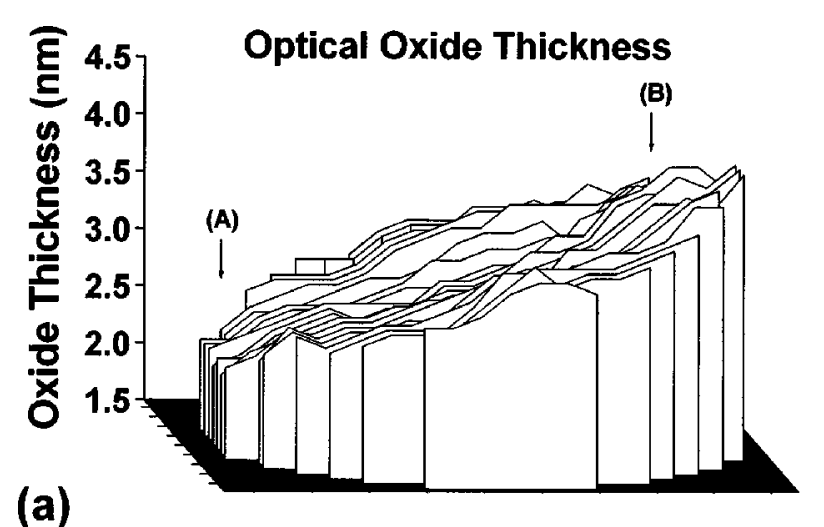

(a)

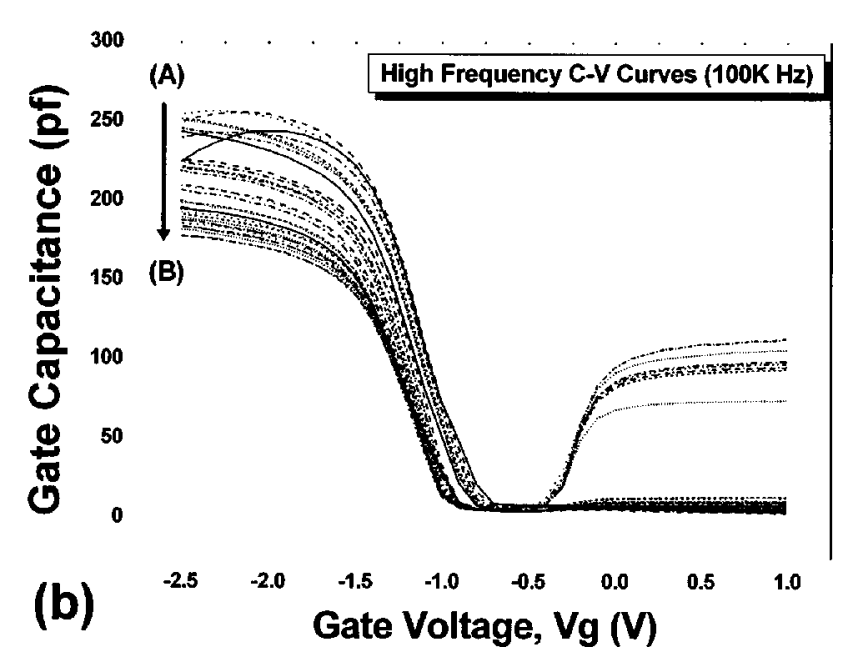

Figure 2. (a) Oxide thickness profile after tilted anodization. Consecutive oxide thickness (A to B) is observed to vary from 20 to $40 \AA$ by ellipsometry. (b) $100 \mathrm{kHz} \mathrm{C-V}$ curves of MOS capacitors from point A to point B. Gate capacitance reduction reveals the thicker $T_{\mathrm{ox}}$ in point $\mathrm{B}$.

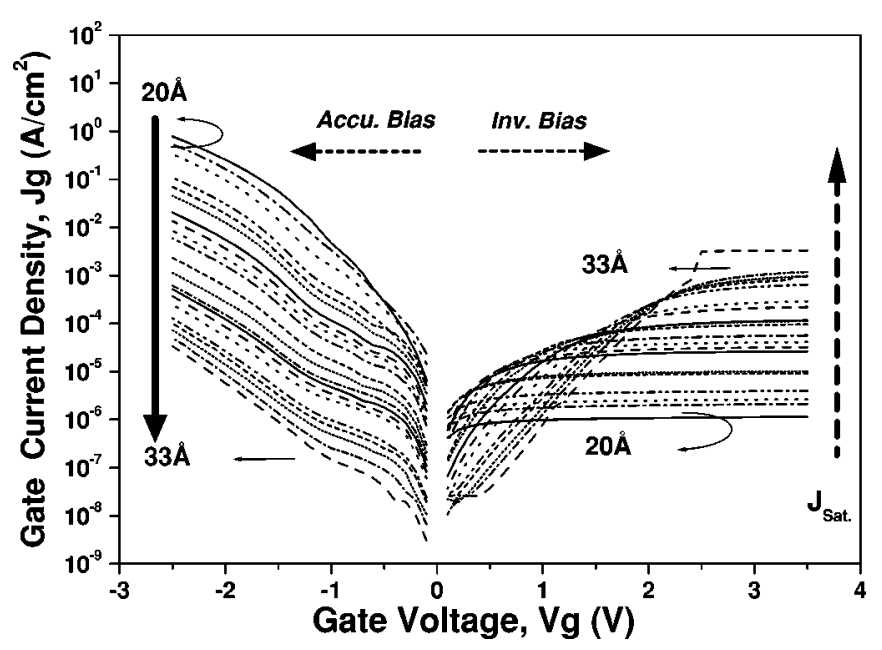

Figure 3. J-V measurements of p-type substrate MOS diodes with gradually increasing oxide thickness. Both the tunneling currents in accumulation $\left(J_{\text {accu }}\right)$ and inversion $\left(J_{\text {inv }}\right)$ regions were measured $J_{\text {accu }}$ and $J_{\text {inv }}$ were observed in contrary trend with $T_{\mathrm{ox}}$.

from 20 to $40 \AA$ (by ellipsometry, $n=1.46$ ) is shown in Fig. 2a. Besides, high-frequency $(100 \mathrm{kHz}) \mathrm{C}-\mathrm{V}$ curves through the p-type substrate (from A to B in Fig. 2a) are shown in Fig. 2b. We can see that when oxide is thin and gate leakage current is high, capacitance drop in accumulation bias is observed due to the series resistance effects. ${ }^{16}$ In addition, the reduction of gate capacitance reveals the increase of $T_{\mathrm{ox}}$ from A to B. After $\mathrm{C}-\mathrm{V}$ measurement, current density-voltage $(\mathrm{J}-\mathrm{V})$ characteristics were analyzed at the same time. Figure 3 displays the J-V plots of MOS diodes in accumulation $\left(J_{\text {accu }}\right)$ and inversion $\left(J_{\text {inv }}\right)$ regions with the gradually increasing oxide thickness (20-33 $\AA$ ). As seen, $J_{\text {accu }}$ decreases regularly by an order of magnitude for every $\sim 2 \AA$ increase in oxide thickness. It is interesting to observe that in the $J_{\text {inv }}$ region, the saturation current $\left(J_{\text {sat }}\right)$ increases with $T_{\text {ox }}$ under high field. But in the low-field region, the currents saturate first when oxides are thin and increase with $T_{\mathrm{ox}}$, as noted previously, and then they become nonsaturated ( $\left.J_{\text {nonsat }}\right)$ and decrease with $T_{\mathrm{ox}}$, which is inconsistent with the simulation result of previous analytical models. ${ }^{14}$

Due to the lack of minority carrier supply in the MOS diode, inversion tunneling current is dominated either by the minority generation rate or the oxide tunneling probability. As shown in Fig. 4, $\mathrm{C}-\mathrm{V}$ curves with $100 \mathrm{kHz}$ were zoomed in to observe the gate voltage sharing by the oxide and the substrate. While oxide is thin $\left(T_{\text {ox }}<25 \AA\right.$, e.g., $\left.T_{\text {ox }}=20 \AA\right)$, the oxide voltage immediately pinned in a specific value and then deep depletion occurred. As a result, the saturated $J_{\text {inv }}$ is observed due to the pinned oxide field as shown in Fig. 3. The subsequent gate bias expands the depletion width, which contributes to the slight increase in $J_{\text {rg-d }}$. However, when oxide gets thicker, e.g., $T_{\mathrm{ox}}>25 \AA$, minority generation rate is large enough to support the tunneling current, thus deep depletion not happens at low field. In this situation, the oxide tunneling mechanism dominates the $J_{\text {in }}$ in the nonsaturated region.

In the analytical model,${ }^{14}$ minority carrier current $J_{\text {minority }}$ dominates $J_{\text {inv }}$, which can be written as

$$
J_{\text {minority }}=J_{\mathrm{s}}+J_{\text {rg-d }}+J_{\text {diff }}
$$

where $J_{\mathrm{s}}, J_{\mathrm{rg}-\mathrm{d}}$, and $J_{\mathrm{diff}}$ are the generation-recombination currents from interface states, bulk traps in the depletion region, and back contact, respectively. However, if we fix the $N_{\mathrm{A}}$ and $D_{\text {it }}$ values in this model, $J_{\text {inv }}$ did not show an apparent increase with $T_{\text {ox }}$. In addition, $\mathrm{SiO}_{2}$ with various oxide thicknesses were grown simultaneously on a single wafer by tilted anodization. Afterward, this wa- 


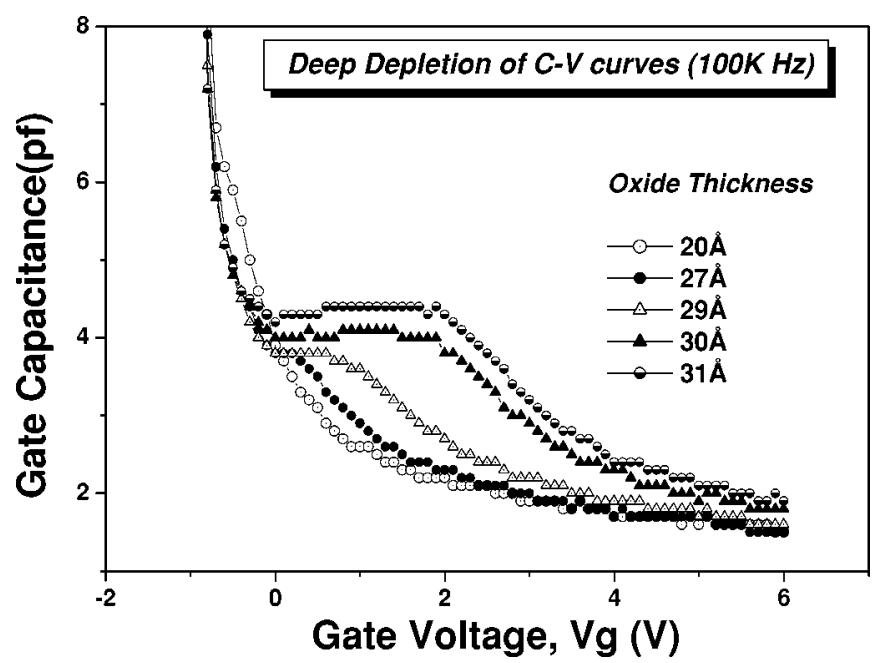

Figure 4. Zoom-in of $100 \mathrm{kHz} \mathrm{C}-\mathrm{V}$ curves with different oxide thicknesses. The deep depletion phenomena occur immediately when oxide is thinner than $25 \AA$. While oxides become thicker $\left(T_{\mathrm{ox}}>25 \AA\right)$, oxides are capable of blocking the inversion current at low field. Deep depletion did not take place until the oxide tunneling probability is larger than the minority carrier generation rate.

fer was treated with the same post-treatments, including PAA, aluminum evaporation, lithography, and etching processes. Therefore, if the $\mathrm{Al} / \mathrm{SiO}_{2}$ interface could be controlled in an identical property, the effect due to various interface states from sample to sample at the $\mathrm{Al} / \mathrm{SiO}_{2}$ can be ignored in the comparison of electrical characteristics.

In another aspect, a great amount of traps and dangling bonds was reported to exist in the suboxide region close to the interface. , $^{5}$ For this reason, we believe the trap-related generationrecombination current should contain two parts. One is $J_{\text {rg-d }}$ as described previously, and the other is the component from the suboxide, $J_{\text {rg-so }}$. In this study, $J_{\text {diff }}$ is generally small and can be neglected. Hence, $J_{\text {minority }}$ can be rewritten as

$$
J_{\text {minority }}=J_{\mathrm{s}}+J_{\text {rg-d }}+J_{\text {rg-so }}
$$

According to the conventional Shockley-Read-Hall (SRH) model, we can describe the inversion current in the form

$J_{\text {inv }}=J_{\text {minority }}=q \cdot\left(\int_{\mathrm{Ev}}^{\mathrm{Ec}} G_{\mathrm{s}} d E+\int_{0}^{\mathrm{W}_{\mathrm{d}}} G_{\mathrm{d}} d x+\int_{0}^{\mathrm{W}_{\mathrm{so}}} G_{\mathrm{so}} d x\right)$

where $G_{\mathrm{s}}, G_{\mathrm{d}}$, and $G_{\mathrm{so}}$ are the thermal generation rates via interface states, and silicon bulk trap in the depletion region and suboxide layer, respectively. In addition, $W_{\mathrm{d}}$ and $W_{\text {so }}$ are the widths of depletion region and suboxide layer, respectively. From the observation, the components of $\int_{\mathrm{Ev}}^{\mathrm{Ec}} G_{\mathrm{s}} d E$ and $\int_{0}^{\mathrm{W}_{\mathrm{so}}} G_{\mathrm{so}} d x$ are mainly responsible for $J_{\text {inv }}$ due to the great generation rate of $G_{\mathrm{s}}$ and $G_{\mathrm{so}}$. $\int_{0}^{\mathrm{W}_{\mathrm{so}}} G_{\mathrm{so}} d x$ is proportional to the amount of suboxide traps, which can be described as $\int_{0}^{\mathrm{w}_{\mathrm{so}}} N_{\mathrm{t} \text {-so }} d x$, where $N_{\mathrm{t} \text {-so }}$ is the trap (or dangling bonds) density in the suboxide region. We believe the $N_{\mathrm{t} \text {-so }}$ shall present different distributions between thick and thin oxides. The thicker oxide exhibits the wider $N_{\text {t-so }}$ distribution that contributes to the thickness-dependent $J_{\text {inv }}$ level.

PMA effect on inversion tunneling current.-From the study, hydrogen migrating through the oxide could be captured by suboxide bonding (suboxide trap). ${ }^{18}$ The PMA process is well known to generate a great amount of hydrogen molecules by the chemical reaction
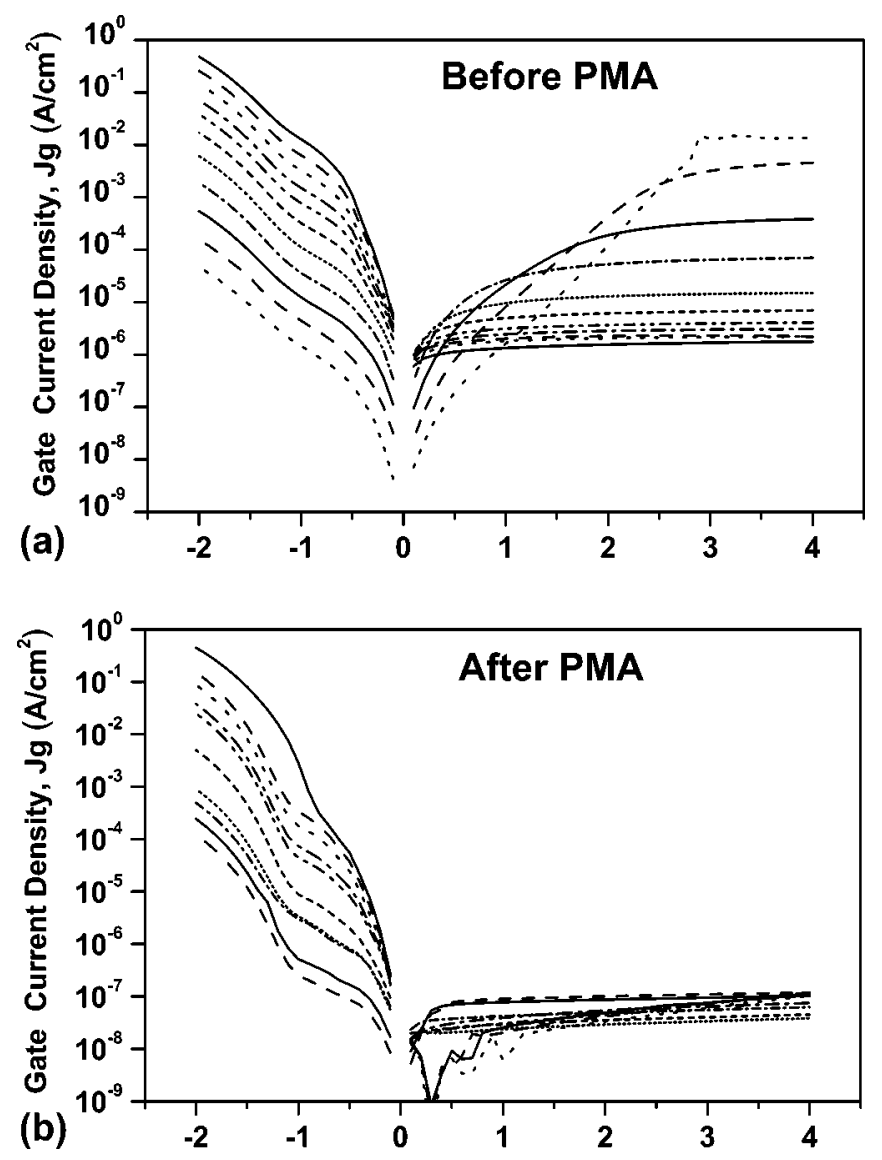

Figure 5. J-V characteristics of p-type substrate MOS diodes (a) before and (b) after $400^{\circ} \mathrm{C} 3$ min PMA treatment in $\mathrm{N}_{2}$ ambient. $J_{\text {inv }}$ drastically decreases after PMA.

$$
3 \mathrm{H}_{2} \mathrm{O}+2 \mathrm{Al} \rightarrow \mathrm{Al}_{2} \mathrm{O}_{3}+3 \mathrm{H}_{2}
$$

In the subsequent discussion, $\mathrm{J}-\mathrm{V}$ curves of MOS diodes were measured before and after $400^{\circ} \mathrm{C}, 3$ min PMA treatment in $\mathrm{N}_{2}$ ambient. As seen in Fig. 5, J-V curves before and after PMA are shown in 5a and $b$, respectively. After the massive hydrogen passivation, it is obvious that $J_{\text {inv }}$ decreases drastically. Moreover, thicknessdependent $J_{\text {inv }}$ magnitude is not apparent after PMA treatment. $\int_{0}^{\mathrm{W}_{\mathrm{so}}} G_{\mathrm{so}} d x$ is proportional to the amount of $\int_{0}^{\mathrm{W}_{\mathrm{so}}} N_{\mathrm{t}-\mathrm{so}} d x$, where $N_{\mathrm{t} \text {-so }}$ is the trap density in the suboxide region. Though the distribution of $N_{\text {t-so }}$ is still unknown, we can see that after the massive passivation in $N_{\text {t-so }}$, suboxide width shows a slight influence on the $J_{\text {inv }}$ magnitude. This result implies the dominant role of $G_{\text {so }}$ in the $J_{\text {so }}$ component.

XPS spectra of 15,25 , and $35 \AA \mathrm{SiO}_{2}$. - To verify the suboxide effects, $T_{\text {ox }}$ with 15,25 , and $35 \AA$ were examined by ex situ XPS using monochromatic $\mathrm{Mg} \mathrm{K} \alpha$ radiation as shown in Fig. 6. On the XPS spectra, stoichiometric $\mathrm{SiO}_{2}\left(\mathrm{Si}^{4+}\right)$ and bulk $\mathrm{Si}\left(\mathrm{Si}^{0}\right)$ correspond to distinguishable binding energies of 103.3 and $99.4 \mathrm{eV}$, respectively. The peaks among $\mathrm{SiO}_{2}$ and $\mathrm{Si}$ are mainly due to the intermediate suboxide bonding. In the plot, the spectra were merged by each detected spectrum under various $T_{\text {ox }}$ values. For example, the first spectrum was detected on the oxide surface, and then a low and constant sputter rate (ionized $\mathrm{Ar}$ at $3 \mathrm{kV}, 0.7 \mu \mathrm{A} / \mathrm{mm}^{2}$ ) was employed to remove the surface oxide (about 1.5-2 $\AA \mathrm{SiO}_{2}$ was removed for each sputter duration). After the 1.5-2 $\AA \mathrm{SiO}_{2}$ was removed, the second spectrum was then detected. By this sequence, when the oxide layer was totally removed, only signal from the bulk 


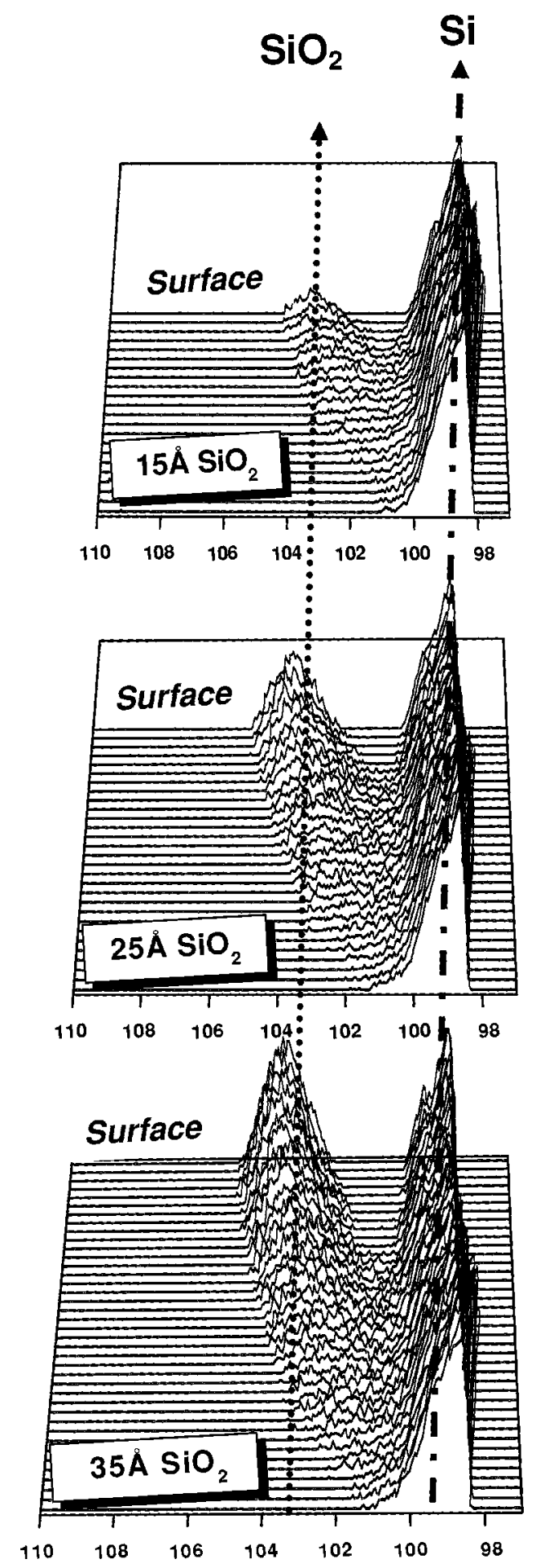

Figure 6. XPS Si $2 p$ spectra of $\mathrm{SiO}_{2}$ with thicknesses of 15,25 , and $35 \AA$ from the oxide surface to the silicon substrate. Ionized $\mathrm{Ar}$ at $3 \mathrm{kV}, 0.7$ $\mu \mathrm{A} / \mathrm{mm}^{2}$ is utilized to sputter the thin oxide layer by layer. The interfacial transition region widths are observed to increase with $T_{\mathrm{ox}}$.

$\mathrm{Si}\left(\mathrm{Si}^{0}\right)$ could be detected. In electron spectroscopy, the surface is either positively or negatively charged, and surface charging leads to signal instability and the shifting of spectra on the energy. In order to avoid the charge effect, we adopt a beam of low-energy electrons to neutralize the surface charge when the $\mathrm{Si}^{0}$ peak was observed to shift to the position not belonging to the steady-state static charge of $\mathrm{Si}^{0}\left(99.4 \mathrm{eV}\right.$ ). In this work, the detected $\mathrm{SiO}_{2}$ is so thin (under $50 \AA$ )

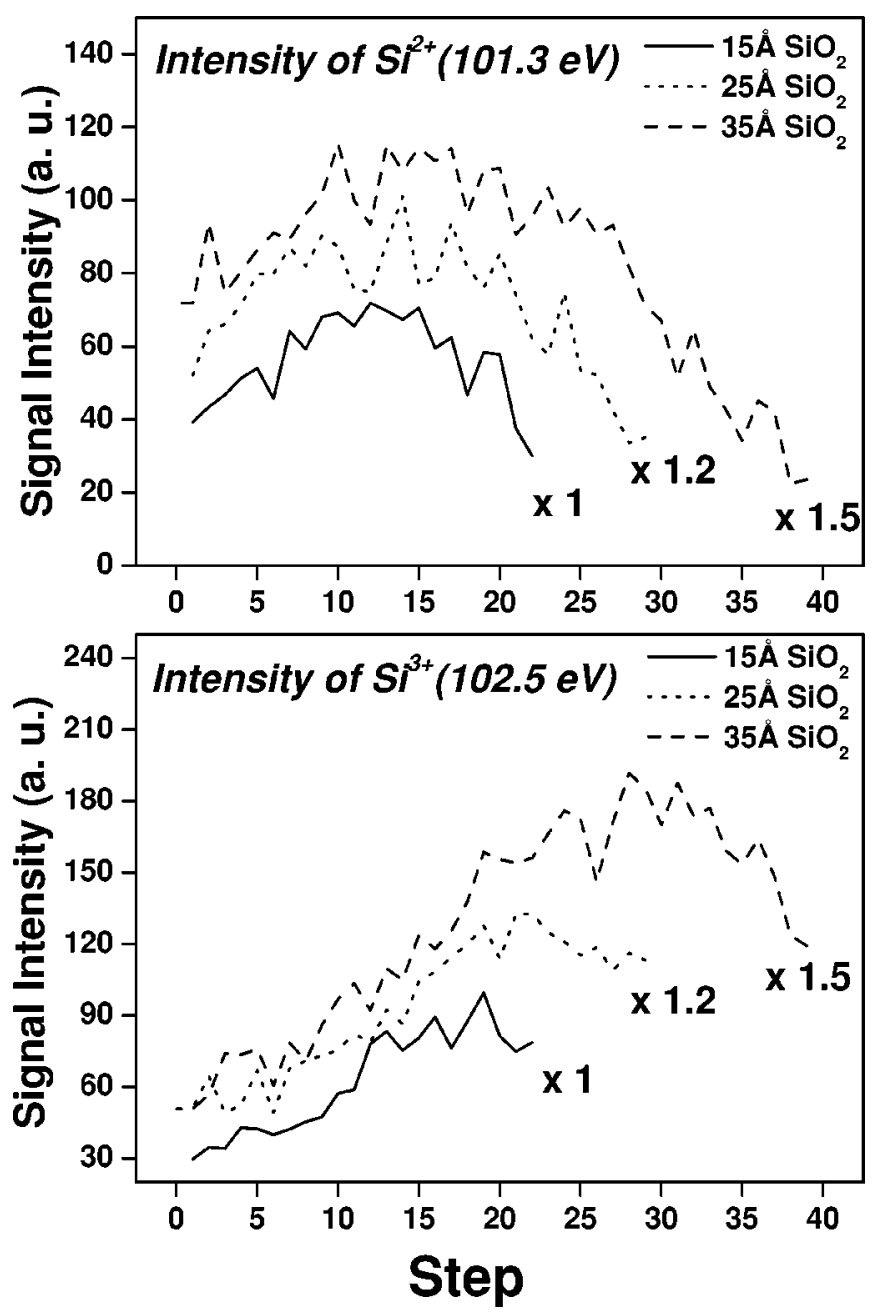

Figure 7. Suboxide bonding intensity of $\mathrm{Si}^{2+}$ and $\mathrm{Si}^{3+}$ from substrate to oxide surface. In order to make the distribution distinct, signal intensities are shown in $\times 1.2$ for $\mathrm{Si}^{2+}$ and $\times 1.5$ for $\mathrm{Si}^{3+}$. The interfacial suboxide width bonding is not confined in a specific region but varies with $T_{\mathrm{ox}}$.

that the $\mathrm{Si}^{0}$ signal from underneath the silicon substrate could always be detected. The small deviation occurring on each spectrum may be attributed to residual charge on the film. However, it does not affect the binding energy of the intermediate oxidation states relative to the bulk $\mathrm{Si}\left(\mathrm{Si}^{0}\right)$. Therefore, we shift all the $\mathrm{Si}^{0}$ peaks to the same standard reference value of $99.4 \mathrm{eV}$ for more accurate comparison. By inspecting the spectra from the surface to the interface, peaks shift and transform from $\mathrm{Si}^{4+}$ to $\mathrm{Si}$. The silicon oxide is observed to contain two parts, i.e., the suboxide-rich layer closed to the interface and the stoichiometric-oxide-rich layer closed to the surface. In spite of the impurity disturbance, changes in peak intensity provide a crude means of suboxide distribution and concentration. From the study, the Si $2 p$ spectrum can be deconvoluted into five admitted bonding configurations, i.e., $\mathrm{Si}^{\mathrm{x}+} x=0-4 .{ }^{19}$ The intensities can be taken according to the relative amount of $\mathrm{SiO}_{x}$. The suboxide peak intensities of $\mathrm{Si}^{2+}(101.3 \mathrm{eV})$ and $\mathrm{Si}^{3+}(102.5 \mathrm{eV})$ were extracted from the spectra as shown in Fig. 7. To prevent the curve overlaps and make the distribution distinct, signal intensities are shown in $\times 1.2$ for $\mathrm{Si}^{2+}$ and $\times 1.5$ for $\mathrm{Si}^{3+}$ from the interface to the $\mathrm{SiO}_{2}$ surface ( step $0 \sim$ step 40 ). We can see that the hill-like distributions are observed in both $\mathrm{Si}^{2+}$ and $\mathrm{Si}^{3+}$ signals. The $\mathrm{Si}^{2+}$ bonding gradually transforms to $\mathrm{Si}^{3+}$ while the spectra get close to the surface. The previous work proposed by Pasquarello et al. ${ }^{12}$ mentioned that the calculation of Si $2 p$ energy shift could be more 


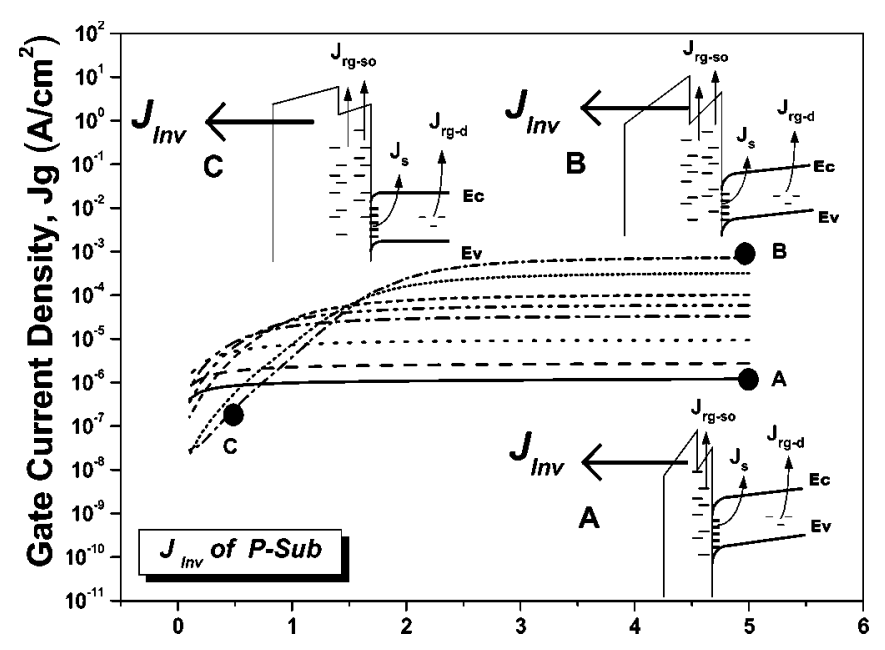

Figure 8. Schematic diagrams of inversion current sources. Condition A: thin oxide in high oxide field; condition B: thick oxide in high oxide field; and condition $\mathrm{C}$ : thick oxide in low oxide field.

accurate with the consideration of core-hole relaxation. They proposed a plausible explanation of the shift of $\mathrm{Si}^{+4}$ peak with oxide thickness. In this work, $\mathrm{SiO}_{2}$ with thicknesses of 15,25 , and $35 \AA$ were detected from the oxide surface to the $\mathrm{SiO}_{2} / \mathrm{Si}$ interface with a constant sputter rate. However, when the thicker oxides, i.e., $\mathrm{SiO}_{2}$ of 25 and $35 \AA$, were sputtered to the thickness of $15 \AA$, the surface Si $2 p$ spectra of these three samples exhibit varied suboxide information under the same oxide thickness. Consequently, we think the effect of Si 2 p core-hole relaxation does not affect the result of oxide-thickness-dependent suboxide width due to the varied oxide thicknesses. From Fig. 7, it is apparent that the suboxide width exhibits a $T_{\text {ox }}$-dependent property where the interfacial suboxide width is not confined in a specific region but varies with $T_{\mathrm{ox}}$. Because a growth of $x$ thickness $\mathrm{SiO}_{2}$ consumes $0.44 x \mathrm{Si}$, the interface region between $\mathrm{SiO}_{2}$ and $\mathrm{Si}$ changes with time during oxidation. We can suspect that suboxide width $w_{\text {so }}$ varies with $T_{\text {ox }}$ initially in the thin oxide regime. More defects and damages could be induced during oxidation in thicker oxide, thus the wider suboxide widths are observed.

Finally, schematic diagrams of $J_{\text {inv }}$ under different gate biases are shown in Fig. 8. As shown in conditions A and B, the gates were biased in the high-field region and $J_{\text {minority }}$ dominates $J_{\text {inv }} . J_{\text {inv }}$ can be written as $J_{\text {inv }} \cong J_{\text {minority }}$; hence, the thicker oxide displays a higher $J_{\text {inv }}$ level. In condition $\mathrm{C}$, while the generation rate is large enough to support the tunneling current and the oxide field is low, oxide tunneling probability dominates $J_{\text {inv }}$ and can be described as $J_{\text {inv }} \cong J_{\text {minority }} \times P\left(E_{\text {ox }}\right)$, where $P\left(E_{\text {ox }}\right)$ is the oxide tunneling probability. A lower field introduces a smaller $P\left(E_{\text {ox }}\right)$ and therefore a smaller $J_{\text {inv }}$.

\section{Conclusions}

In this study, we found that the $\mathrm{SiO}_{2} / \mathrm{Si}$ interfacial suboxide region varies with $T_{\mathrm{ox}}$. In addition, the traps in the suboxide region provide a great amount of generation-recombination centers, which contribute to the $J_{\text {inv }}$ level significantly. We believe the study of the $J_{\text {inv }}$ behavior as proposed in this work is helpful to recognize the suboxide characteristics and useful in the novel MOS tunneling diode applications.

\section{Acknowledgment}

The authors thank the NTU Instrument Center for supporting the electron spectroscopy for chemical analyses, and the National Science Council of Republic of China for supporting this work under contract no. NSC-92-2215-E-002-002.

National Taiwan University assisted in meeting the publication costs of this article.

\section{References}

1. B. Brar, G. D. Wilk, and A. C. Seabaugh, Appl. Phys. Lett., 69, 2728 (1996).

2. Y. H. Shih and J. G. Hwu, IEEE Electron Device Lett., 22, 299 (2001).

3. C. W. Liu, M. H. Lee, M.-J. Chen, I. C. Lin, and C.-F. Lin, Appl. Phys. Lett., 76, $1516(2000)$.

4. C. W. Liu, W. T. Liu, M. H. Lee, W. S. Kuo, and B. C. Hsu, IEEE Electron Device Lett., 21, 307 (2000).

5. T. J. Maloney, D. E. Aspnes, H. Arwin, and T. W. Sigmon, Appl. Phys. Lett., 44, 517 (1984).

6. Y. Wei, R. M. Wallace, and A. C. Seabaugh, Appl. Phys. Lett., 69, 1270 (1996).

7. F. J. Grunthaner, P. J. Grunthaner, R. P. Vasquez, B. F. Lewis, J. Maserjian, and A. Madhukar, Phys. Rev. Lett., 43, 1683 (1979).

8. S. Horiguchi and H. Yoshino, J. Appl. Phys., 58, 1597 (1985).

9. F. J. Himpsel, F. R. McFeely, A. Taleb-Ibrahimi, J. A. Yarmoff, and G. Hollinger, Phys. Rev. B, 38, 6084 (1988).

10. J. W. Keister, J. E. Rowe, J. J. Kolodziej, H. Niimi, H.-S. Tao, T. E. Madey, and G. Lucovsky, J. Vac. Sci. Technol. A, 17, 1250 (1999).

11. A. C. Diebold, D. Venables, Y. Chabal, D. Muller, M. Weldon, and E. Garfunkel, Mater. Sci. Semicond. Process., 2, 103 (1999).

12. A. Pasquarello, M. S. Hybertsen, and R. Car, Phys. Rev. B, 53, 10942 (1996)

13. W. C. Lee and C. Hu, in Proceedings of VLSI Symposium, p. 198 (2000).

14. M. Y. Doghish and F. D. Ho, IEEE Trans. Electron Devices, 39, 2771 (1992).

15. Y.-C. Chen, C.-Y. Lee, and J.-G. Hwu, Solid-State Electron., 45, 1531 (2001).

16. K. J. Yang and C. Hu, IEEE Trans. Electron Devices, 46, 1500 (1999).

17. K. Yang, Y.-C. King, and C. Hu, in Proceedings of the VLSI Symposium, p. 77 (1999).

18. S. T. Pantelides, S. N. Rashkeev, R. Buczko, D. M. Fleetwood, and R. D. Schrimpf, IEEE Trans. Nucl. Sci., 47, 2262 (2000).

19. K. T. Queeney, M. K. Weldon, J. P. Chang, Y. J. Chabal, A. B. Gurevich, and J. Sapjeta, J. Appl. Phys., 87, 1322 (2000). 